INTERNATIONAL JOURNAL OF MULTIDISCIPLINARY RESEARCH AND ANALYSis

ISSN(print): 2643-9840, ISSN(online): 2643-9875

Volume 05 Issue 02 February 2022

DOI: 10.47191/ijmra/v5-i2-31, Impact Factor: 6.072

Page No. 452-457

\title{
New Anthropometric Indicators are associated with Glycemic Control in Type II Diabetics with Excess Weight
}

\author{
Larissa Albuquerque ${ }^{1}$, Liana Andrade Oliveira ${ }^{2}$
}

\begin{abstract}
Objective: To evaluate the association of new anthropometric indicators with glycemic control in overweight patients with type II diabetes.

Methods: The sample consisted of 164 type II diabetic patients selected for convenience. Demographic, socioeconomic variables and time since diabetes diagnosis were collected using a structured questionnaire. Anthropometric measurements of weight, height, waist circumference (WC) and hip circumference were taken. The Body Mass Index (BMI), BodyShape Index (ABSI), BodyShapeRoundness Index (BRI) and Body Adipose Index (BAI) indicators were calculated. The 12-hour fasting blood samples were collected by means of digital puncture by a trained professional. Patients were classified into two groups: controlled $(\leq 130$ $\mathrm{mg} / \mathrm{dL}$ ) and altered (>130 mg/dL) glycemia. To evaluate models adjusted for glycemic control (dependent variable) and new indicators (independent variables), logistic regression was used.

Results: There was a correlation of the new anthropometric indicators with the body mass index. It was observed that there were no differences in the means of BMI, WC and the new indicators (ABSI, BRI, IAC) between glycemic control status. The new anthropometric indicators were not associated with glycemic control in type II diabetics, only ABSI in women was associated with altered glycemia $(O R=3.81 ; p=0.040)$. Conclusion: We conclude that the $A B S I$ anthropometric method in women is associated with glycemic control in patients with type 2 diabetes mellitus.
\end{abstract}

KEYWORDS: Diabetes; Overweight; Anthropometry

\section{INTRODUCTION}

Diabetes mellitus (DM) is a metabolic disease, caused by the body's resistance to insulin and/or no production of insulin by the body. Type 2 diabetes mellitus represents about $95 \%$ of the diagnosed cases of diabetes mellitus. The diabetic is characterized by chronic hyperglycemia, disturbances in the metabolism of carbohydrates, fats, proteins, originating from a defective secretion and/or action of insulin in the tissues - target(1).

The treatment of diabetes is predominantly with glycemic control. For adequate verification of diabetes, regardless of type, extensive self-care is required, with efficient glycemic control, as high glycemic levels are related to serious microangiopathic (diabetic retinopathy, diabetic nephropathy and distal sensory neuropathy) and macroangiopathic (ischemic heart disease) complications. , peripheral vascular disease, stroke). It is believed that the control of overweight and obesity is a determining factor for effective glycemic control, however it is estimated that $90 \%$ of patients with type 2 diabetes mellitus (DM2) are overweight, thus presenting possible negative consequences in their complex treatment( 2.3).

Thus, an effective tracking of changes in body composition, common in overweight, can help to reduce the consequences and complications of diabetes mellitus. Anthropometry thus stands out as a non-invasive, low-cost method and is the most used to assess body composition. In recent decades, new indicators and formulas have been proposed to more accurately estimate body adiposity. Bearing in mind that the classic use of the body mass index (BMI) did not guarantee reliable results from this perspective $(4,5)$.

The body mass index (BMI) was ordinarily used by health professionals in the assessment of dietary status and mortality risk. However, this index does not provide information on the distribution and proportion of body fat(5).

New anthropometric indicators have emerged in recent years(4), three of which stand out here: BodyShape Index $(A B S I)(6,7)$, BodyShapeRoundness Index (BRI)(8) and Body Adipose Index (BAI)(9). The BodyShape Index (ABSI) is based on waist circumference adjusted by height and BMI(6,7). The BodyShapeRoundness Index (BRI) is a body shape indicator capable of predicting total and 


\section{New Anthropometric Indicators are associated with Glycemic Control in Type II Diabetics with Excess Weight}

visceral body fat(8).The Body Adipose Index (BAI) can be used to check the percentage of body fat in men and women of different ethnicities(8).

Given these new anthropometric indicators and the need for more careful tracking and monitoring of body adiposity for effective treatment of diabetes, the objective of the present study was to evaluate the association of new anthropometric indicators with glycemic control in patients with DM2.

\section{MATERIAL AND METHODS}

Outline

This is a cross-sectional study that used baseline data from a double-blind, placebo-controlled clinical trial that evaluated the effect of tamarind flour consumption in patients with type II diabetes conducted between 2016 and 2017.

This research was submitted to and approved by the Research Ethics Committee of the University of Fortaleza, with CAAE 30308114.1.0000.5534 and was registered in the Brazilian Platform for Clinical Trials (RBR-4xzjny). All participants signed an informed consent form. The study was funded by the National Council for Scientific and Technological Development (CNPq), through the Call MCTI/CNPq/MS - SCTIE - Decit No. 07/2013

\section{Location and Population}

The research was carried out at the Integrated Center for Diabetes and Hypertension of Ceará, a reference institution in the treatment of diabetes. The study population consisted of diabetic patients treated at the aforementioned institution. The sample consisted of 164 type II diabetic patients selected for convenience.

Inclusion criteria for the study were: presence of type 2 diabetes mellitus diagnosed for at least 2 years; be over 20 years of age; being overweight or grade I obesity according to the body mass index (BMI)(10,11); be using oral hypoglycemic agents (metformin hydrochloride, glibenclabin and/or glicazide). As exclusion criteria, use insulin; having another known chronic illness; the presence of pregnancy.

Data collect

Demographic, socioeconomic variables and time since diabetes diagnosis were collected using a structured questionnaire.

Anthropometry

Anthropometric measurements of weight, height, waist circumference (WC) and hip circumference (HC) were taken. Weight and height data were obtained on a properly calibrated digital anthropometric scale, Balmak, with a capacity of $150 \mathrm{~kg}$ with a variation of $50 \mathrm{~g}$, measuring up to 2.00 meters with a graduation of $0.5 \mathrm{~cm}$. Waist and hip circumferences were measured according to WHO recommendations(12) using an inelastic measuring tape.

The following anthropometric indicators were calculated:

Body mass index (BMI)

$\mathrm{BMI}=($ Body weight $(\mathrm{kg})) /\left(\right.$ Height $\left.(\mathrm{m})^{2}\right)$

ABSI (Total)

$A B S I=(C C(m)) /\left(\llbracket B M I\left(k g / m^{2}\right) \rrbracket \wedge(2 / 3) X \llbracket\right.$ Height $\left.(m) \rrbracket \wedge(1 / 2)\right)$

ABSI (Men)

$A B S I=(C C(m)) /\left(\llbracket B M I\left(k g / m^{2}\right) \rrbracket \wedge(2 / 3) X \llbracket\right.$ Height $\left.(\mathrm{m}) \rrbracket \wedge(1 / 2)\right)$

ABSI (Women)

$A B S I=(C C(m)) /\left(\llbracket B M I\left(k g / m^{2}\right) \rrbracket \wedge(3 / 5) X \llbracket\right.$ Height $\left.(m) \rrbracket \wedge(1 / 5)\right)$

BRI

$\varepsilon=V\left(1-\left(\left((C C(m) / 2 \pi)^{2}\right) /\left((0.5 \times \text { Height }(m))^{2}\right)\right)\right)$

$\mathrm{BRI}=364.2-(365.5 \times \varepsilon)$

IAC

$\mathrm{IAC}=(\mathrm{CQ}(\mathrm{cm})) /($ Height $(\mathrm{m}) \times \mathrm{V}($ Height $(\mathrm{m})))-18$

fasting blood glucose

To measure fasting blood glucose ( $\mathrm{mg} / \mathrm{dL}$ ) for 12 hours, the Cholestech LDX device (Alere company) was used. Blood samples were collected by means of a digital puncture by a trained professional.

Patients were classified into two groups: controlled glycemia ( $\leq 130 \mathrm{mg} / \mathrm{dL}$ ) and altered (>130 $\mathrm{mg} / \mathrm{dL}$ ) as recommended by the Brazilian Society of Diabetes - SBD(2) and American Diabetes Association - ADA(13). 


\section{New Anthropometric Indicators are associated with Glycemic Control in Type II Diabetics with Excess Weight}

Data analysis

Demographic, socioeconomic variables and time of diagnosis were compared according to glycemic control using the chi-square test. The new anthropometric indicators (ABSI, BRI and IAC) were correlated with BMI using Pearson's correlation. Means of anthropometric indicators were also compared with glycemic status using Student's t test. Finally, to evaluate models adjusted for glycemic control (dependent variable) and new indicators (independent variables), logistic regression was used. $p<0.05$ was considered significant.

\section{RESULTS}

In the analyzed patients, there was an equal proportion of men and women, most were aged 60 years or older (57.9\%, $\mathrm{n}=95$ ), 88.4\% $(n=145)$ were non-white and $51.2 \%(n=84)$ had more than 12 years of schooling. $78.7 \%(n=129)$ reported receiving more than 1 minimum wage and $58.5 \%(n=96)$ had more than 10 years of diagnosis of type II diabetes. After stratification by glycemic control, it was observed that there was no difference between the groups in the analyzed demographic, socioeconomic and time of diagnosis variables (Table 1 ).

There was a correlation between the new anthropometric indicators and the body mass index (Figure 1). BMI showed a positive correlation with WC $(r=0.660 ; p<0.001)$. BRI showed a moderate positive correlation with BMI $(r=0.713 ; p<0.001)$. With the percentage of fat, estimated by the IAC, there was a moderate positive correlation with BMI $(r=0.513 ; 0<0.001)$. ABSI (Men, Women, Total) was not correlated with BMI ( $p>0.05)$.

In Table 2, it was observed that there were no differences in the means of BMI, WC and the new indicators (ABSI, BRI, IAC) between glycemic control status. The means of anthropometric variables were $29.3(2.32) \mathrm{kg} / \mathrm{m}^{2}$ for BMI, $101.4(6.76) \mathrm{cm}$ for WC, 0.084 (0.004) for ABSI (Men), 0.121 (0.005) for ABSI ( Women), 0.085 (0.004) for ABSI (Total), 6.47 (1.24) for BRI and 34.26 (5.71) \% for IAC.

The new anthropometric indicators were not associated with glycemic control in type II diabetics (Table 3). With the exception of ABSI (Women), in which women with the highest tertile of ABSI were more likely to have altered blood glucose, after adjustment for time of diagnosis, self-reported race, age and $B M I(O R=3.81 ; p=0.040)$.

\section{DISCUSSION}

This study aimed to evaluate the association of new anthropometric indicators with glycemic control in patients with DM2. It was observed that only $A B S I$ in women was associated with glycemic control regardless of time of diagnosis, self-reported race, age and BMI.

The study of the new indicators used here is still incipient and scarce, and there is no consensus on their superiority over traditional indicators. In Brazil, Rezende(3) observed that the new indicators ( $A B S I, B R I$ and IAC) were not superior to traditional anthropometric indices (BMI and WC) to discriminate diabetes. In another study, it was observed that ABSI and BRI were also not more efficient in identifying diabetes compared to BMI and WC. However, BRI had a better performance in identifying obesity and a higher correlation with diabetes compared to ABSI(14).

The BRI has been considered effective as a predictor of body fat(15), so it could be used to assess health conditions and diagnose chronic diseases, such as type 2 diabetes mellitus. However, in the present study, the BRI was not associated with control glucose in diabetics.

In a similar study, the ABSI showed low discriminant power in the identification of chronic diseases(16). Here, $A B S I$ in women was the only indicator that was associated with glycemic control, in which women with the highest ABSI were more likely to have altered blood glucose, after adjustment for confounding factors ( $O R=3.81 ; p=0.040$ ).

In a study, IAC was evaluated to estimate the percentage of body fat and the incidence of type 2 diabetes mellitus. It was observed that IAC did not show a good response in the quantification of body fat, compared to waist circumference in men and hip circumference in women, and it was also not considered a good predictor for diabetes(17).

Corroborating this, another study that used the IAC to estimate body fat in athletes with type 2 diabetes mellitus, it was observed that the IAC presented limited performance for the prediction of fat percentage in elite athletes with diabetes, especially when compared to other methods such as bioimpedance analysis or skinfold prediction models, thus showing that it was also not a good predictor for the identification of diabetes(18).

Although interesting, our findings have some limitations, such as: the complexity of formulas that make it difficult to calculate quickly and immediately, thus making it a time-consuming and ineffective method for faster care in outpatient clinics. Another limitation was the fact that the volunteers used drugs for the treatment of diabetes, as well as other types of drugs, which may influence our findings, often masking the measurement of fat mass and lean body mass influenced by water retention. 


\section{New Anthropometric Indicators are associated with Glycemic Control in Type II Diabetics with Excess Weight}

\section{CONCLUSION}

We conclude that the ABSI anthropometric method in women is associated with glycemic control in patients with type 2 diabetes mellitus. Indicators such as BRI and IAC were not associated with glycemic control. The use of these indicators in clinical practice still requires investment in technologies to facilitate their immediate calculation.

\section{REFERENCES}

1) Rathmann W, Giani G. Global prevalence of diabetes: estimates for the year 2000 and projections for 2030. Diabetes care. 2004: 27(10), 2568-2569.

2) Sociedade brasileira de diabetes - SBD. Diretrizes da Sociedade Brasileira de Diabetes: 2015-2016. São Paulo: AC Farmacêutica, 2016.

3) Rezende, FAC. Capacidade preditiva e associação de indicadores antropométricos com diabetes mellitus, hipertensão arterial e comprometimento da capacidade funcional em idosos. Universidade Federal de Viçosa. Teste de doutorando, 2016.

4) Maessen MF, Eijsvogels TM, Verheggen RJ, Hopman MT, Verbeek AL, de Vegt F. Entering a new era of body indices: the feasibility of a body shape index and body roundness index to identify cardiovascular health status. PLoSOne, 2014: 9(9), e107212.

5) Carneiro IBP, Sampaio HADC, Carioca AAF, Pinto FJM, Damasceno NRT. Oldand new anthropometricindices as insulinresistancepredictors in adolescents. Arquivos Brasileiros de Endocrinologia \& Metabologia,2014: 58(8), 838-843.

6) Malerbi DA, Franco L. Multicenter study of the prevalence of diabetes mellitus and impaired glucose tolerance in the urban Brazilian population aged 30-69 yr. Diabetes care, 1992: 15(11), 1509-1516.

7) Krakauer NY,Krakauer JC. A new body shape index predicts mortality hazard independently of body mass index. PloS one, 2012: 7(7), e39504.

8) Cheung, Y. B. "A Body Shape Index" in middle-age and older Indonesian population: scaling exponents and association with incident hypertension. PloS one, 2014: 9(1), e85421.

9) Thomas DM, Bredlau C, Bosy-Westphal A, Mueller M, Shen W, et al. Relationships between body roundness with body fat and visceral adipose tissueemerging from a new geometrical model. Obesity (Silver Spring), 2013: 21(11): 2264-2271.

10) Bergman RN,Stefanovski D, Buchanan TA., Sumner AE, Reynolds JC, Sebring NG, Watanabe RM. A better index of body adiposity. Obesity, 2011: 19(5), 1083-1089.

11) World health organization - WHO. Obesity: Preventing and managing the global epidemic. Report of a WHO consultation of obesity.Genova, 1998.

12) Lipschitz DA. Screening for nutritional status in the elderly. Primary care, 1994: 21(1), 55.

13) World health organization - WHO. Technical Report Series 894 . Obesity: preventing and managing the global epidemic. World Health Organization, Geneva, 2000.

14) American Diabetes Association. Standards of medical care in diabetes -2016 abridged for primary care providers. Clinical diabetes: a publication of the American Diabetes Association, 2016: 34(1), 3.

15) Chang Y, Guo X, Chen Y, Guo L, Li Z, Yu S et al. A Body Shape Index and Body Roundness Index: Two new body indices to identify diabetes mellitus among rural populations in northeast China. Journal of the American College of Cardiology. 2015;66(16):C114.

16) Thomas D, Bredlau C, Bosy-Westphal A, Mueller M, Shen W, Gallagher D et al. Relationships between body roundness with body fat and visceral adipose tissue emerging from a new geometrical model. Obesity. 2013;21(11):2264-2271.

17) Park J, Lim Y, Lee H, Kim T, Choi Y, Min Y et al. Comparison of anthropometric measurements associated with the risk of endoscopic erosive esophagitis: A cross-sectional study. Obesity Research \& Clinical Practice. 2017.

18) Schulze $M$, Thorand B, Fritsche $A$, Häring $H$, Schick F, Zierer A et al. Body adiposity index, body fat content and incidence of type 2 diabetes. Diabetologia. 2012;55(6):1660-1667.

19) Ramírez R, González K. Bodyadiposity index in Colombian elite athletes: A comparisonbetweenthebodymass index andothermeasures. Revista Colombiana de Cardiología. 2015;22(1):22-26.

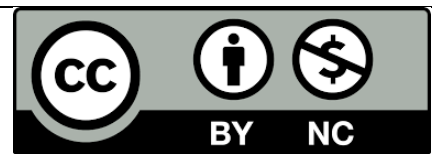

There is an Open Access article, distributed under the term of the Creative Commons Attribution - Non Commercial 4.0 International (CC BY-NC 4.0)

(https://creativecommons.org/licenses/by-nc/4.0/), which permits remixing, adapting and building upon the work for non-commercial use, provided the original work is properly cited. 
New Anthropometric Indicators are associated with Glycemic Control in Type II Diabetics with Excess Weight

TABLES

Table 1. Comparison of demographic, socioeconomic variables and time of diagnosis between glycemic control.

\begin{tabular}{|c|c|c|c|c|}
\hline \multirow[t]{3}{*}{ Variables } & \multicolumn{3}{|l|}{ Fasting glucose (mg/dL) } & \multirow[t]{3}{*}{ p* } \\
\hline & Controlled blood glucose & Altered blood glucose & Total $(n=164)$ & \\
\hline & $\leq 130(n=77)$ & $>130(n=87)$ & & \\
\hline Gender & & & & 0,639 \\
\hline Male & $37(48,1 \%)$ & $45(51,7 \%)$ & $82(50,0 \%)$ & \\
\hline Female & $40(51,9 \%)$ & $42(48,3 \%)$ & $82(50,0 \%)$ & \\
\hline Age group & & & & 0,087 \\
\hline$<60$ anos & $27(35,1)$ & $42(48,3)$ & $69(42,1)$ & \\
\hline$\geq 60$ anos & $50(64,9)$ & $45(51,7)$ & $95(57,9)$ & \\
\hline Self-declared race & & & & 0,348 \\
\hline No- white & $70(90,9 \%)$ & $75(86,2 \%)$ & $145(88,4)$ & \\
\hline White & $7(9,1 \%)$ & $12(13,8 \%)$ & $21(11,6)$ & \\
\hline Education & & & & 0,861 \\
\hline$<12$ anos & $37(48,1 \%)$ & $43(49,4 \%)$ & $80(48,8)$ & \\
\hline$\geq 12$ anos & $40(51,9 \%)$ & $44(50,6 \%)$ & $84(51,2)$ & \\
\hline Family income & & & & 0,829 \\
\hline$\leq 1 \mathrm{SM}$ & $17(22,1 \%)$ & $18(20,7 \%)$ & $35(21,3)$ & \\
\hline$>1 \mathrm{SM}$ & $60(77,9 \%)$ & $69(79,3 \%)$ & $129(78,7)$ & \\
\hline Diagnosis time & & & & 0,353 \\
\hline$\leq 10$ anos & $29(37,7 \%)$ & $39(44,8 \%)$ & $68(41,5)$ & \\
\hline$>10$ anos & $48(62,3 \%)$ & $48(55,2 \%)$ & $96(58,5)$ & \\
\hline
\end{tabular}

*Chi-square test. Values expressed in $\mathrm{n}(\%)$.

Figure 1. Correlation of WC, ABSI (Men, Women, Total), BRI, IAC with IMC.
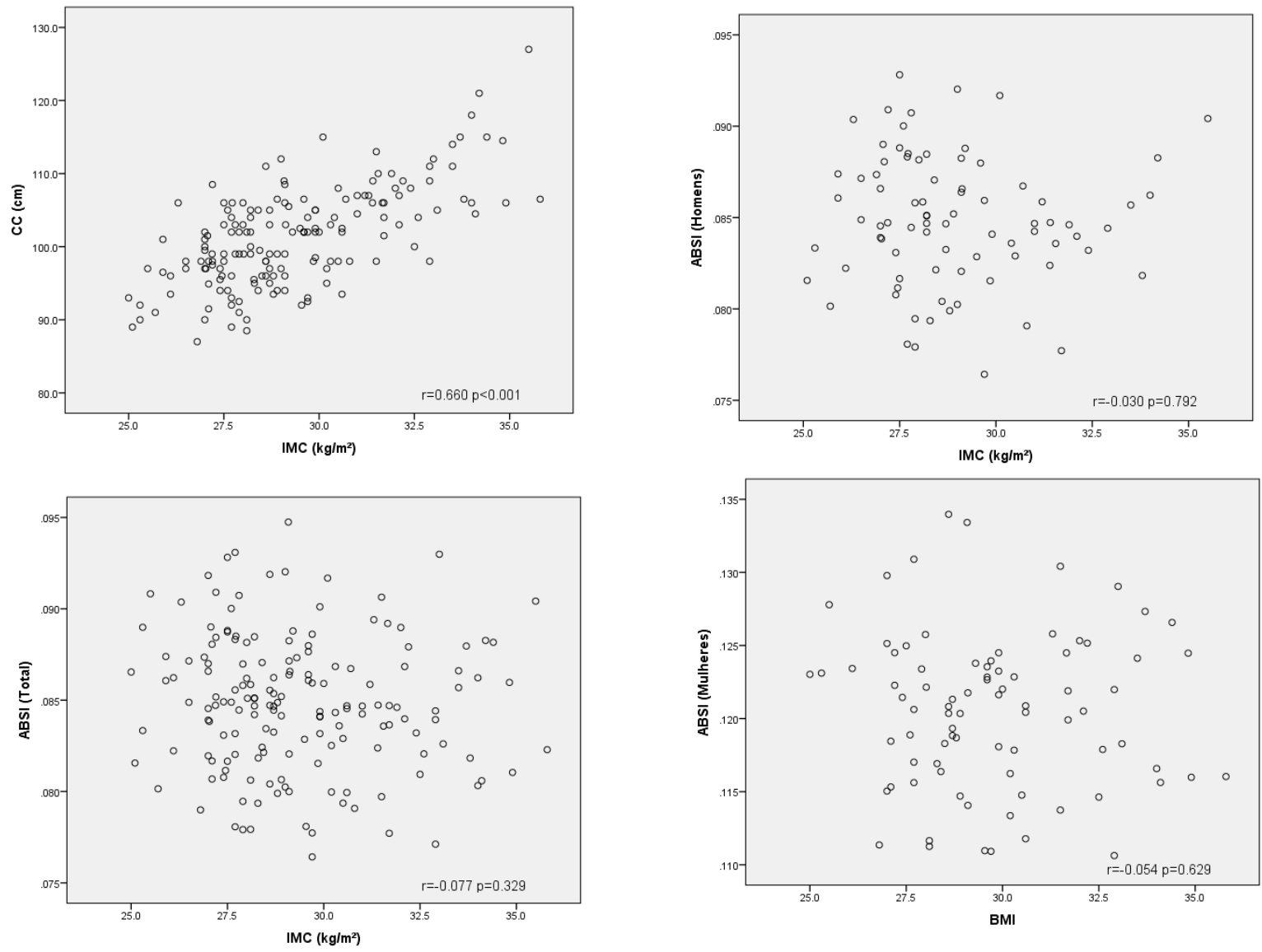

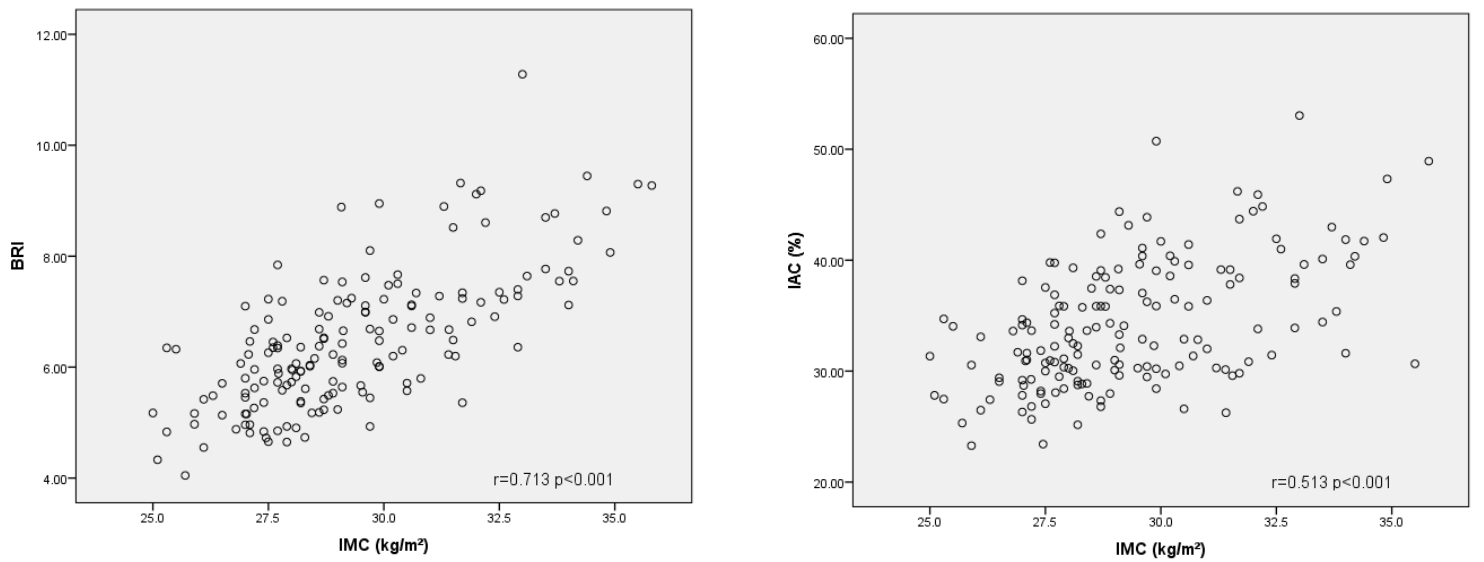

Table 2. Comparison of anthropometric variables between glycemic control.

\begin{tabular}{lllll}
\hline Anthropometric variables & \multicolumn{2}{l}{ Fasting blood glucose $(\mathbf{m g} / \mathbf{d L})$} & $\mathbf{p}^{*}$ \\
\hline & Glicemia controlada & Glicemia alterada & Total & \\
\hline IMC, (kg/m & $\leq 130$ & $>130$ & & \\
CC, (cm) & $29,58(2,35)$ & $29,13(2,32)$ & $10,3(2,34)$ & 0,214 \\
ABSI (Men) & $101,41(6,72)$ & $101,31(6,83)$ & $101,41(6,76)$ & 0,922 \\
ABSI (Woman) & $0,085(0.004)$ & $0,084(0,003)$ & $0,084(0,004)$ & 0,593 \\
ABSI (Total) & $0,120(0,005)$ & $0,121(0,005)$ & $0,121(0,005)$ & 0,187 \\
BRI & $0,085(0,004)$ & $0,085(0,003)$ & $0,085(0,004)$ & 0,668 \\
IAC, \% & $6,57(1,27)$ & $6,37(1,21)$ & $6,47(1,24)$ & 0,295 \\
& $35,11(6,28)$ & $33,51(5,08)$ & $34,26(5,71)$ & 0,075 \\
\hline
\end{tabular}

*Student's $t$ test. Values expressed as mean and standard deviation.

Table 3. Chance of altered blood glucose between tertiles of anthropometric variables.

\begin{tabular}{lll}
\hline Variáveis antropométricas & Oddsratio & $\mathbf{p}^{*}$ \\
\hline ABSI (Men) & & \\
$1^{\circ}$ tercil & Reference & \\
$2^{\circ}$ tercil & 2,31 & 0,208 \\
$3^{\circ}$ tercil & 2,63 & 0,182 \\
ABSI (Woman) & & \\
$1^{\circ}$ tercil & Reference & \\
$2^{\circ}$ tercil & 1,60 & 0,438 \\
$3^{\circ}$ tercil & 3,81 & 0,040 \\
ABSI (Total) & & \\
$1^{\circ}$ tercil & Reference & \\
$2^{\circ}$ tercil & 1,99 & 0,105 \\
$3^{\circ}$ tercil & 1,97 & 0,134 \\
BRI & & \\
$1^{\circ}$ tercil & Reference & \\
$2^{\circ}$ tercil & 1,02 & 0,961 \\
$3^{\circ}$ tercil & 1,60 & 0,399 \\
IAC, \% & & \\
$1^{\circ}$ tercil & Reference \\
$2^{\circ}$ tercil & 0,92 & 0,854 \\
$3^{\circ}$ tercil & 0,58 & 0,436
\end{tabular}

Model adjusted for time of diagnosis, self-reported race, age and body mass index. ${ }^{*}$ Model adjusted for time of diagnosis, selfreported race, age, body mass index, and sex. 